\title{
Critical Care Airway Management eLearning modules
}

\begin{abstract}
The Australasian College of Emergency Medicine (ACEM) has recently launched Critical Care Airway Management eLearning modules to support emergency medicine trainees in developing their airway management skills in the emergency department. A team of Emergency Physicians and trainees worked collaboratively to develop the eLearning resources ensuring extensive stakeholder consultation. A comprehensive resource manual was written to provide learners with knowledge that underpins the modules. ACEM provided project coordination as well as administrative and technical team support to the production. Although specifically developed with early ACEM trainees in mind, it is envisaged the resources will be useful for all emergency clinicians. The project was funded by the Australian Commonwealth Department of Health.
\end{abstract}

\section{Introduction}

Airway management, including rapid sequence induction of anaesthesia and endotracheal intubation (RSI), is a core skill of Specialist Emergency Physicians. A United Kingdom audit of airway management found that major complications and avoidable deaths occur in the emergency department (ED) with greater frequency than in the operating theatre ${ }^{1}$. In the ED, a failure of clinicians to anticipate and plan for failure, or to follow recommended practice for airway rescue when difficulties occurred, alongside contributory human factors of poor communication or teamwork, poor leadership and task fixation, were responsible for adverse outcomes $^{2}$.

The Australian and New Zealand Airway Registry investigators found that RSI first attempt success rate in Australasian EDs positively correlated with team leader and intubator seniority, and intubation experience. Novice intubators (those having performed less than 10 intubations) attempted $12 \%$ of all intubations, with a significantly lower success rate, prompting the investigators to opine that this procedure should be learned in the controlled operating theatre or simulation environment, rather than in the $\mathrm{ED}^{3}$.

\section{Critical care eLearning modules}

With increasing trainee numbers in Emergency Medicine (EM) and other critical care specialties, there is increased competition for the available training opportunities. Clinical encounters involving airway management can be stressful and high stakes for all trainees, but especially for junior trainees. The Australasian College for Emergency Medicine (ACEM) Curriculum Revision Project identified that airway management was a skill that EM trainees required earlier than they could reliably access in all training hospitals. As a result, ACEM committed to creating alternative pathways for skills acquisition, including the development of online critical care eLearning modules ("the modules").

This is the author manuscript accepted for publication and has undergone full peer review but has not been through the copyediting, typesetting, pagination and proofreading process, which may lead to differences between this version and the Version of Record. Please cite this article as doi: $10.1111 / 1742-6723.12902$ 
Teaching a learner to simply intubate a manikin would provide training in only the technical skill. The concept for the modules was scenario-based eLearning packages matched with simulation manikins. It was recognised that clinical scenarios were required to re-create the rich, complex and time pressured environment that surrounds ED airway management. This would allow learners to develop critical decision making skills along with their procedural skills. The scenarios were planned to include all the steps from awake patient through to stable ventilated patient, aiming to teach intubation as a skill in context, and not in isolation. It was decided that the focus would be on the operator; what they know, think and do, in such a way as the learner sees themselves as Dr Y, the trainee "star" of the modules. Dr Y would be working within a team embedded within a complex hospital system, as occurs in clinical practice. The extensive theory that underpins airway management would be made available in a separate resource manual, thus allowing realistic flow of the module scenarios.

The Critical Care Enhancement Project was funded by the Australian Commonwealth Department of Health through ACEM's Emergency Medicine Program. The project aims to provide additional educational opportunities for EM trainees to enhance their management of the critically ill patient, specifically to allow trainees to develop airway skills through deliberate practice. An aligned competitive grant process supporting Australian emergency departments to purchase critical care simulation equipment, which suited the educational needs of their department, occurred in 2016.

\section{Development of the modules}

The critical care Authoring Group was comprised of eight fellows of ACEM, two ACEM trainees from across Australasia and an ACEM project co-ordinator. The group worked collaboratively in two phases to create eLearning modules and the airway resource manual. In the writing phase from September 2014 to November 2015, scenarios were written and edited, followed by a production phase from May 2016 to June 2017. Due to staff changes and other constraints, work was not continuous over these periods.

Work began with a face to face workshop to create a series of clinical scenarios. These were designed to enable the learner to consider a variety of airway problems and incrementally develop the necessary skills to manage them in the ED. From that initial work, a framework was designed to lead the learner from bag valve mask (BVM) ventilation then to simple uncomplicated direct laryngoscopic intubation, use of video laryngoscope (VL) and other intubation techniques and finally to airway complications requiring surgical airway. A further module assumed competence with all equipment and focused on cases with complexities beyond airway management. There was a purposeful decision not to include management of the paediatric airway, but to cover that as a separate module if time and funding allowed.

Following the workshop, the scenarios were written by individuals within the Authoring Group. Each scenario was then reviewed at various stages by the Authoring Group and consensus reached through email discussion, phone conference webinars and face to face meetings. This process brought together a wealth of knowledge and experience from the 
group, providing trainees with expert opinion as they work through the modules. A similar process of review was employed for the airway resource manual.

\section{Behind the scene preparation: ACEM logistics, administrative and technical support}

Throughout the development of the modules and manual by the Authoring Group, a broad range of both internal and external stakeholders was consulted: ACEM Fellows and trainees, Directors of EM and Directors of EM Training, dual Fellows (FACEM-FCICM and FACEMFANZCA), members of ACEM Education \& Training and Communications \& Engagement Departments, and ACEM committees (Specialist Training \& Assessment and Trainee).

Feedback was sought on the accuracy of the clinical content and presentation. The ACEM project coordinator collated the feedback responses and in consultation with the Authoring Group chairperson, edited the modules to ensure the text matched the images and there was consistency in language, terminology, grammar and punctuation. Final approval was granted by the Council of Education in June 2017.

The modules were produced by an external eLearning production organisation who provided guidance on educational styles, methods and trends. A project co-ordinator was appointed by the company to act as the conduit with ACEM. Content, graphic and instructional designers provided expertise on module design as well as guidance on educational strategies to engage learners. The company developed a storyboard for each module, followed by the build of the actual eLearning modules.

On average, each module took approximately 10 weeks to produce, including content production by the Authoring Group, storyboard development by the eLearning organisation, review by stakeholders, module build and another two rounds of review.

The images and procedural videos were produced by ACEM Communications \& Engagement, with members of the Authoring Group playing the medical and airway nurse roles. To enhance the realism of the scenario-based modules, the video and image production took place at two Melbourne hospitals' simulation centres.

\section{Resource manual}

While this project aims to promote access to skills and attitudes necessary to guide junior EM trainees in their quest for airway experience, it was also recognised that the knowledge that underpins these modules is extensive. As such, it was felt that a document outlining this knowledge was required.

The 'Resource Manual for Airway Management in the Emergency Department' was designed so it could be read from start to finish, as well as 'dipped' into to learn or revise areas of content. Written by and from the perspective of Emergency Physicians rather than 'airway experts', it used both newly written material and existing resources, particularly from Emergency Life Support (ELS) and Dr James Hayes, FACEM. Initial editing was undertaken by a single person on the working group to provide a unified voice. Following this, multiple 
iterations were undertaken related to review by the remainder of the working group and outside reviewers.

The decision to present the manual in digital format was made so as not only to emphasise key points but also provide background and further reading. The manual is referred to throughout the modules, directing trainees to the relevant sections as required. In addition, other resources are suggested and referenced in recognition of the variety of practice in this area.

\section{How to use and navigate the modules}

The Critical Care Airway Management eLearning resources are based upon the critical care requirement of the EM specialist training program. The modules target ACEM trainees and contain information to complement learning across the different training stages of the specialist program. Although specifically developed with early ACEM trainees in mind, the modules are now freely available as open access medical education, as it is envisaged they will be useful for all emergency clinicians - including medical, nursing and allied health staff and paramedics.

The modules contain the knowledge that underpins airway management, and focus on what the trainee 'needs to know' rather than 'how to' manage a particular clinical issue. The content was the choice of the authors, with the intent to display a variety of practices, thereby exposing EM trainees to broader experience across the modules.

The module series consists of a resource manual and four scenario-based modules:

Resource Manual for Airway Management in the ED - pre-reading and an ongoing resource containing the theory behind the airway modules.

Module 1: Uncomplicated airway management - two scenarios covering BVM ventilation, direct laryngoscopy and intubation.

Module 2: Alternate intubation techniques - one scenario that has two branches showing:

a) intubation with endotracheal tube over bougie, and

b) intubation by video laryngoscope (VL).

Module 3: The unexpected challenging airway - one scenario of a toxicology case revisited from module 1 - that has two branches demonstrating;

a) can't intubate, can't ventilate (via BVM) - managed with laryngeal mask airway then VL to intubate, and

b) can't intubate, can't oxygenate and an emergency surgical airway.

Module 4: Other complicating factors - two scenarios covering high risk intubations in more complex cases - asthma and sepsis.

Each module takes approximately 60 minutes to complete with an EM trainer/supervisor and/or fellow trainees, using a manikin in a simulation training session. Each scenario provides background information (patient information, pre-hospital care, type of ED, available staff) and the timeline of events as they unfold. The learner assumes the role of ED registrar (Dr Y) and is provided with Dr Y's thoughts, words and actions. Through this 
process, learners have the opportunity to reflect on their own current practice and competencies.

These learning resources are suitable to a variety of learning modalities. They can be undertaken by an individual trainee, or a small number of trainees working together with an airway task trainer to set the constructs of the scenario and allow repeated deliberate practice (self-directed and peer learning). They may also be used as a teaching tool by a trainer who can use the scenarios to guide simulation sessions, or as a case study for further discussion, eg use of checklists, team approach, role of video laryngoscope etc. They can be a valuable tool for other team members, such an emergency nurse who is about to step into the role of an airway nurse as they allow access to the thought process of the airway operator, and run through the sequence of intubation step by step.

Functionality embedded in the modules allows users to navigate through the stages of each module. They can follow links, skip or repeat sections, and track their progress using various "drop down" menu options and progress bars.

Important links to note include:

Guidelines for use (for trainees and trainers)

Mapping of Learning Outcomes relating to Airway Management across the ACEM Curriculum Framework, Critical Care Accreditation Guidelines (Intensive Care and Anaesthetics) and the airway modules

Interactive procedural videos within the modules and resource manual

Further learning resources (checklists, reflection questions, registry and data collection forms)

Module evaluation survey (link at the end of each module)

Certificate of Completion (for CPD records)- provided to logged in participants (currently limited to ACEM trainees and FACEMs), and free full open access for all critical care providers is currently planned.

Refer to 'Figures 1,2 and 3' for images of the modules.

\section{Discussion}

The face of education has changed significantly in the last two decades with advanced technology encompassing newer research on human learning behaviour and the introduction of new approaches to education such as 'blended learning' and the 'flipped classroom', which have respectively increased the flexibility and personalisation of learning ${ }^{4}$ and provided greater interactivity, active participation, access to experts, and retention of material in emergency medicine education ${ }^{5}$. Blended learning refers to the combination of approaches to learning and teaching using a variety of delivery modes (such as eLearning, multimedia and face to face instruction) and the 'flipped classroom' exchanges the traditional format of a classroom lecture and homework problem set. ${ }^{5}$ 
The future of eLearning with 'the net generation' is evolving to 'personal learning environment (PLE) ${ }^{\prime}$. In the newer ways of learning, the instructor is no longer a spectator but he/she works alongside the team, contributing, facilitating, participating and guiding the team in eLearning environments. eLearning is an active, interactive and reflective method of learning and provides a platform to enhance learning, using the facilitator to support the process and add value to the topic being learnt ${ }^{7}$. As we learn more about human learning behaviour, abstract learning through textbooks is slowly being replaced with contextual learning processes like Problem Based Learning (PBL) and eLearning ${ }^{8}$.

Inbuilt quality and flexibility in this eLearning resource is designed to meet the training needs of time constrained front-line clinicians, who have shift patterns in ED such that finding time for formal lessons is not easy. Learners who are proactive often benefit more from eLearning $^{9}$. EDs are adapting to eLearning, although some at a greater rate than others. The modules are designed to keep learners engaged alone or as a group. However, facilitation from teachers will further enhance learning outcomes through interaction and discussion. Technology and infrastructure in most parts of Australia is sufficiently developed to support eLearning and also provide distant education, although not always in the ED workplace ${ }^{10}$. The eLearning process necessitates change in physical, technological, structural, managerial processes and resources and above all, cultural change $\mathrm{e}^{11,12}$.

In group learning sessions, as well as knowledge, several other desirable characteristics are learnt including teamwork, listening skills, respect of the opinions of others, sharing and division of responsibility ${ }^{13}$. Group sessions combined with simulation and discussion can create opportunities for deliberate practice, where training is focused on improving particular tasks to contribute to expert performance ${ }^{14}$. The modules are designed to be delivered as problem based learning (PBL) exercises, should that be the choice of teaching for the facilitator. Learning from peers is a developmental process for humans ${ }^{15,16}$. A peer group PBL process is highly effective, quicker and less confronting to the learners ${ }^{17}$. The module scenarios are designed to be real with instructions that are simple to follow and implement. The modules build towards more complex challenges which offer further developmental learning.

\section{Conclusion}

The Critical Care Airway Management eLearning modules and resource manual have been developed with the aim of mitigating or preventing adverse airway management events in EDs with a tailored educational program for learners early in EM training. The secondary aim was to tackle an emerging clinical training bottleneck - uncertain universal and timely access to anaesthetic rotations for ACEM trainees.

It is anticipated that these resources will be used to guide deliberate, technical, cognitive and human factor skills acquisition during simulated patient encounters, by individual or groups of learners, facilitated by an expert, or used peer to peer. The resources have the potential to 
be customised and further developed, for example to include paediatric or neonatal cases, or lessons from critical incidents, or the use of new equipment or drugs. Such a resource has certain benefits over sole reliance on experience gained during a term rotation, which will depend on the enthusiasm of the supervisor, the patient case-mix, and other site specific limitations.

The concept of 'social software' is emerging wherein consumers become producers and their needs dictate a way forward for new learning. ACEM has taken a step into the future PLE of its members and others who use this resource.

Critical Care Airway Management Modules can be accessed on the ACEM website.

\section{References}

1. Royal College of Anaesthetists. 4th National Audit Project: Major Complications of Airway Management in the UK. London: Royal College of Anaesthetists, 2011

2. O'Sullivan E, Laffey J, Pandit JJ. A rude awakening after our fourth 'NAP': lessons for airway management. Anaesthesia. 2011; 66: 331-334.

3. Alkhouri H, Vassiliadis J, Murray M. et al. Emergency airway management in Australian and New Zealand emergency departments: A multicentre descriptive study of 3710 emergency intubations. Emergency Medicine Australasia. 2017; 29 (3): 1-9.

4. Lateef L. Blended Learning in Emergency Medicine: Implementing the E-Learning component. South East Asian Journal of Medical Education. 2014; 8(1): 60-65.

5. Young T, Bailey C, Guptill M, Thorp A, Thomas T. The Flipped Classroom: A Modality for Mixed Asynchronous and Synchronous Learning in a Residency Program. West. J. Emerg. Med. 2014; 15(7): 938-944.

6. Atwell G. Personal learning environments: The future of elearning? eLearning Papers. 2007; 2: 1-7. Available from www.elearningpapers.eu (Accessed Retrieved 4 March, 2008).

7. Berge ZL. Active, interactive, and reflective elearning. The Quarterly Review of Distance Education. 2002; 3(2): 181-190.

8. Bannan-Ritland B. Computer-mediated communication, eLearning, and interactivity: A review of the research. Quarterly Review of Distance Education, 2002; 3(2): 16179.

9. Ericsson K Anders. Deliberate Practice and the Acquisition and Maintenance of Expert Performance in Medicine and Related Domains. Academic Medicine. 2004; 79(10): 70-81. 
10. Cook V, McCarthy S. Review of Internet Access and Usage in Emergency Departments. ACI Emergency Care Institute, 2014.

11. O'Neill K, Singh G, O'Donoghue J, Cope C. Implementing eLearning programmes for Higher Education: A review of the literature. Journal of Information Technology Education. 2004; 3: 313-323.

12. Stojanovic L, Staab S, Studer R. eLearning based on the Semantic Web. In WebNet2001-World Conference on the WWW and Internet ; 2001. Available from URL: http://www.aifb.kit.edu/web/Inproceedings481/en (Accessed 2017 March).

13. Hung W, Jonassen DH, Liu R. Problem-based learning. Handbook of research on educational communications and technology. New York: Erlbaum, 2008; 485-506.

14. Ericsson,KA. Deliberate Practice and Acquisition of Expert Performance: A General Overview. Academic Emergency Medicine. 2008; 15(11): 988-994.

15. Kilroy DA. Problem based learning. Emergency Medicine Journal. 2004; 21(4), 411413.

16. Wood DF. Problem based learning. BMJ. 2003; 326 (7384): 328-330.

17. Wutoh R, Boren SA, Balas EA. ELearning: a review of Internet-based continuing medical education. Journal of Continuing Education in the Health Professions.

2004; 24(1): 20-30. 


\section{Author contributions}

All authors contributed to the development of e-module resources. All authors contributed to the manuscript preparation and review, and approved the final version. EM chaired the Critical Care Authoring Group.

\section{Critical care authoring group}

for producing the content and structure of the modules

Dr Elizabeth Mowatt, FACEM (Chair, Dr C - Team leader)

Dr Bronwyn Peirce, FACEM

Dr Ruth Osborne, FACEM

A Prof Sally McCarthy, FACEM

Dr Belinda Hibble, FACEM

A Prof Deepak Doshi, FACEM (Dr Y)

Dr Geoff Hawking, FACEM

Dr Rajeev Jarugula, FACEM

Dr Naveed Aziez, ACEM Trainee (Dr X)

Dr Jeram Hyde, previous ACEM Trainee

Angela Cahill, Project Coordinator- Critical Care (Nurse A)

Meggan Jenkins, Project Coordinator-Critical Care (previous)

\section{Acknowledgements}

Dr James Hayes, FACEM (Northern Hospital, Epping) - for significant clinical content Dr Anthony Lewis, FRCA, FANZCA (i-Simulate) - for production of monitor images Emergency Life Support (ELS) course - for significant clinical content Emergency Care Institute, Agency for Clinical Innovation, NSW - for clinical content Learning Seat, E-learning Production - for design and production of modules Royal Melbourne Hospital Emergency Department and Epworth Simulation Centre, Richmond - for use of simulation labs/equipment for images / videos, and assistance by their clinical educators;

Cam Thompson \& Aimee Han, ACEM Lead Content Producer - for images and videos and manual design and compilation

ACEM Specialist Training and Accreditation Committee and Council of Education - for feedback/input on content/structure

\section{Competing interests}

None declared

\section{Authors}

Associate Professor Deepak Doshi FACEM, FCEM, MPS, DCH(London), MHSM, MRCS A\&E(Edin), MRCS(Glas), MS, MBBS

Deputy Executive Director Medical Services, Rockhampton Hospital, Rockhampton, Queensland, Australia.

Associate Professor Sally McCarthy 
MBBS, FACEM, MBA

Emergency Physician, Prince of Wales Hospital, New South Wales, Australia

Faculty of Medicine, The University of New South Wales, Sydney, New South Wales,

Australia

Dr Elizabeth Mowatt

MBBS, GradCertMedEd, FACEM

Emergency Physician \& Clinical Lead EMET Cairns Hub, Cairns Hospital, Cairns,

Queensland, Australia

Angela Cahill

RN, BSc, AdvDipBusMan

Critical Care Project Coordinator, Australasian College for Emergency Medicine, Melbourne,

Australia

Associate Professor Bronwyn Peirce

MBBS, GradCertRRM, FACEM

Emergency Physician, Bunbury Regional Hospital, Rural Clinical School of Western

Australia, University of Western Australia, Bunbury, Australia

Dr Geoff Hawking

MBBS, FACEM, CCPU

Emergency Physician, Bunbury Regional Hospital; Clinical Senior Lecturer, University of

Western Australia, Bunbury, Australia

Dr Ruth Osborne

MBBS (hons), FACEM

Emergency Physician, Austin Health; Medical Demonstrator, Melbourne University,

Victoria, Australia

Dr Belinda Hibble

MBBS, FACEM, MPH, CertWH, GradCertEmrgHlth (Aeromedicine \& Retrieval)

Emergency Physician, University Hospital Geelong and St John of God (Geelong) Hospital;

Clinical Senior Lecturer, Deakin University, Geelong, Victoria, Australia

Katharine Ebbs

B.A.,Grad.Dip.Ed.(Sec.), MMED (Master Educational Studies), CAPM

Education Resources Manager, Australasian College for Emergency Medicine, Melbourne, Victoria, Australia. 


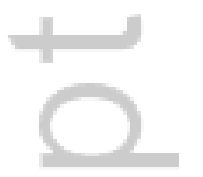




\section{University Library}

\section{- M M N E R VA A gateway to Melbourne's research publications}

Minerva Access is the Institutional Repository of The University of Melbourne

\section{Author/s:}

Doshi, D;McCarthy, S;Mowatt, E;Cahill, A;Peirce, B;Hawking, G;Osborne, R;Hibble, B;Ebbs, $\mathrm{K}$

Title:

Review article: Critical Care Airway Management eLearning modules

Date:

2018-12-01

\section{Citation:}

Doshi, D., McCarthy, S., Mowatt, E., Cahill, A., Peirce, B., Hawking, G., Osborne, R., Hibble, B. \& Ebbs, K. (2018). Review article: Critical Care Airway Management eLearning modules. EMERGENCY MEDICINE AUSTRALASIA, 30 (6), pp.743-748. https:// doi.org/10.1111/1742-6723.12902.

Persistent Link:

http://hdl.handle.net/11343/293870 